\title{
Impacts of Relative Advantage of Fast Food Restaurant's O2O Service and Consumer Involvement on Consumer Engagement, and Store Loyalty: Focused on MZ Generations in Untact Consumption Era
}

\author{
Young-Eun LEE ${ }^{1}$, Yong-Ki LEE ${ }^{2}$
}

Received: May 06, 2020 Revised: June 10, 2020 Accepted: June 10, 2020.

\begin{abstract}
Purpose: Fast food franchise companies are trying a variety of innovative services to increase their competitiveness in response to changes in population composition in the fast food market and rapid changes in consumption trends due to technological development. From this point of view, franchise companies that have focused on offline store operations are providing O2O (offline to online) service as a core service for customer convenience. This new attempt is a strategy to increase loyalty by applying an interaction method based on understanding the characteristics of new generation consumers. However, existing studies are focused on the relationship between $\mathrm{O} 2 \mathrm{O}$ service and acceptance, so very little is known about how $\mathrm{O} 2 \mathrm{O}$ service affects customer loyalty. Therefore, this study examines the impacts of customer involvement and relative advantages of fast food O2O service on customer brand engagement (cognitive and affective engagement) and store loyalty for MZ(Millennials $-Z$ ) generations. Research design, data, and methodology: In order to achieve the purposes of this research, several hypotheses were developed. The data were collected from 247 questionnaires in their 16-30s and were analyzed using SPSS 22.0 and SmartPLS 3.0 program. Measurement model analysis was carried out to assess convergent and discriminant validity. Also, common method bias was tested using the values of VIF (variance inflation factor). The hypotheses was tested using structural equation modeling. Result: First, involvement has a positive effect on cognitive and affective engagement. Second, relative advantages have has a positive effect on cognitive and affective engagement. Third, cognitive influences affective engagement. Finally, both cognitive and affective engagement affect store loyalty, but affective engagement has a stronger effect on store loyalty than cognitive engagement. Conclusions: In the process of consumer-brand interaction, it was confirmed that store loyalty was influenced by cognitive and affective engagement sequentially. However, the results show that affective engagement has a relatively stronger on store loyalty than cognitive engagement. Therefore, it is necessary to establish an $\mathrm{O} 2 \mathrm{O}$ service strategy to maintain long-term loyal customers by inducing cognitive participation with high-involved consumer, as well as affective interaction, in order to obtain new customers and increase customer loyalty.
\end{abstract}

Keywords : Involvement, Customer Brand Enagement, Untact, O2O, MZ Generation.

JEL Classification Code : L10, L2, L8

\section{1. 서론}

\footnotetext{
1 First Author's Affiliation: Doctoral Candidate, Graduate School of Business, Sejong University, Senior Consultant, Lotte Data Communication Company, Seoul, Korea, Email: lee.youngeun@hotmail.com

2 Corresponding Author's Affiliation: Professor, School of Business, Sejong University, Seoul, Korea, Email: yongki2@sejong.ac.kr

(c) Copyright: Korean Distribution Science Association (KODISA)

This is an Open Access article distributed under the terms of the Creative Commons Attribution Non-Commercial License (https://creativecommons.org/licenses/by-nc/4.0/) which permits unrestricted non-commercial use, distribution, and reproduction in any medium, provided the original work is properly cited.
}

인구구성의 급격한 변화와 4 차 산업기술발달, 코로나 19 의 팬데믹(세대 대유행)으로 인해 과거 어느 때보다 소비 트렌드가 빠르게 변화함에 따라 시장과 기업은 새로운 전략 수립이 필요하게 되었다. 소비재 시장에서 주 소비층으로 부상하는 20-30 세대 청년들의 소비 패턴은 이전 세대와 구분되어, 전통적인 마케팅으로는 $\mathrm{MZ}$ 세대 (1980 1994 년 출생 밀레니얼 세대와 1995 년 이후에 출생한 Z 세대를 아우르는 신조어)를 공략하기 어려워졌다. 따라서 과거와는 완전히 달라진 새로운 고객을 선점하지 않으면 미래가 없다는 위기감이 높아지고 있다(Jun, 2020). 예를 들면, 패스트푸드업계도 혼밥족의 증가, 
건강과 가성비를 중시하는 트렌드의 확산으로 기존 브랜드들이 고전을 하고 있다. 따라서 기업들은 가성비 높이기, 1 인 가구 맞춤형 세트 개발 등 트렌디한 신제품의 지속적 출시뿐 아니라, 배달 역량 강화 등 사업부문의 다변화를 통하여 $\mathrm{MZ}$ 세대를 공략할 필요성이 높아지고 있다 (Kim, 2020).

글로벌 패스트푸드 기업들은 시장변화에 발맞춰 경쟁력을 높이기 위한 다양한 노력을 하고 있으며, 맥도날드 본사의 경우 고객 편의, 가치, 경험 제고를 통한 고객 수 증가를 목표로 디지털 기기 도입을 통한 매장 경험 개선, AI 기술 매장 적용 및 배달 강화로 실질적 성과를 창출하였고, 이러한 노력의 결과로 4년만에 '19 년 BCG 혁신기업 50위 (Manly, 2019) 안에 요식업 기업으로 유일하게 다시 등재되었다. 또한 중국 KFC 는 안면인식 결제 서비스와 로봇 서빙시스템을 도입하였고, 미국 도미노 피자는 자율주행자동차를 이용한 배달 서비스를 시범운영 중이다. 이처럼 개인화된 메뉴 추천, 자동화된 주문·배달 시스템 등 푸드테크의 중요성이 점점 부각되고 있다(Lee, \& Jang, 2019). 우리나라 패스트푸드 기업들도 저성장 시대에 맞게 키오스크(무인계산대)를 도입하고 새로운 메뉴, 중저가 마케팅 등 경영효율성과 고객 만족도를 높임으로써 실적개선에 효과를 보고 있다(Km, 2020). 이러한 기조에서 오프라인 매장 운영에 주력했던 프랜차이즈 기업들은 $\mathrm{O} 2 \mathrm{O}($ 온라인과 오프라인 연결) 서비스를 확대해 가고 있다. 맥도날드, 롯데리아, KFC 등 주요 프랜차이즈 기업들은 모바일로 주문과 결제가 가능한 스마트 오더, 테이블 오더 서비스를 선보였고, 예약 픽업, 위치기반 매장선택 및 배달 서비스를 강화하고 있다. 이렇게 $\mathrm{O} 2 \mathrm{O}$ 서비스는 트렌드를 넘어 고객편의를 위한 핵심서비스로 자리잡는 추세이며, 타 업체와는 차별화된 서비스를 제공하는 것이 새 고객을 유치할 수 있는 경쟁력으로 떠오르고 있다(Jo, 2018).

앞으로 4 차산업 혁명과 함께 모바일, 로봇과 인공지능의 발전으로 언택트(비대면)소비 환경이 만들어지고, 새로운 세대와 사회환경의 요구에 따라, 패스트푸드 업계에는 더욱더 다양한 O2O 기반 차별화된 서비스로 오프라인 서비스를 온라인으로 연결·확장하기 위해 경쟁하게 될 것이다. 따라서 소비자와의 상호작용의 방식이 변화함에 따라 소비자를 이해하는 역량이 중요하며, 소비자의 자발적 참여와 긍정적인 경험의 축적과정을 통해 심리적 유대를 형성함으로써 고객의 충성도를 높이는 것이 기업의 장기 생존력을 높일 것이다.

특히 기존에는 기업의 효율성과 $\mathrm{MZ}$ 세대 소비자들이 언택트 시장 성장을 이끌었으나 전세계적으로 COVD-19 가 언택트서비스 시장을 촉진시키고 있다는 분석이 나오며(Nam, 2020), 현재 코로나 팬데믹으로 위축된 오프라인 서비스 산업의 대안으로 급부상하고 있다. 외식업에서는 배달서비스와 같이 대면 접촉을 피할 수 있는 비즈니스 모델이 해당업종의 급격한 감소를 완충시켰다 (삼정 KPMG 경제연구원, 2020). 이러한 급격한 사회변화로 로봇과 인공지능(AD), 블록체인 등 정보통신기술(ICT)를 흡수한 푸드테크가 '언택트'시대 외식문화 혁신을
주도할 것으로 기대된다(이호승, 심희진, 2020). 최근에는 이러한 언택트 현상을 넘어 사람간의 물리적 거리는 유지하되 개인 일상의 삶을 영위하고 사회가 정상적으로 운영되기 위해, 언제든 원할 때 서로 연결할 수 있는 '연결의 필요성' 이 대두되면서 온택트(Ontact 언택트+연결)가 보편화되는 뉴노멀 시대에 접어들고 있다. 따라서 이러한 사회변화에 외식 프랜차이즈 기업들도 온라인 플랫폼을 기반으로 고객과의 소통강화를 위해 디지털 연결성을 확보하는 디지털 트랜스포메이션을 통해 온택트 시대를 대비해야 할 것이다.

그러나 지금까지 패스트푸드 외식업 산업분야의 디지털 트랜스포메이션 관련 연구에 있어서는 쳇봇, 키오스크와 같이 개별 혁신 서비스 수용 및 지속사용의도에 대한 주제 위주로 연구(Byun, 2019; Cha \& Seo, 2020; Cha \& Shin, 2019; Hwang \& Kim, 2019; Jung, 2020)가 이루어지고 있다. 소비자들이 전반적으로 인식하는 상대적인 이점과 고객의 태도와 충성도에 미치는 영향과 같이 고객중심 시각에서 기업비즈니스에 미치는 다양한 연구는 아직까지 부족한 상태이다.

따라서 본 연구에서는 패스트푸드 외식업에 대해 청년 고객들이 생각하는 관여도와 $\mathrm{O} 2 \mathrm{O}$ 기반 서비스 혁신의 우수성에 대한 인식을 파악하고, 이러한 인식이 충성도에 미치는 영향을 파악하기 위하여 고객 브랜드 인게이즈먼트의 개념을 사용하고자 한다. 고객 브랜드 인게이즈먼트는 최근 현대적이고 점차 역동적인 대화형 비즈니스 환경을 반영하여 상당한 관심을 받아오고 있으며(Hollebeek, Srivastava, \& Chen, 2019; Pansari \& Kumar, 2017), 소비자 행동 결과에 대한 향상된 예측 및 설명력을 제공하는 유망한 개념으로 여겨지고 있다(Annet \& Higgins, 2006; Pham \& Amet, 2009). 특히, 언택트소비가 증가하고 고객과의 온라인 소통이 확산되는 환경에서 고객들의 자발적인 인게이즈먼트 역할에 대한 연구가 필요한 시점이라 할 수 있다. 고객 인게이즈먼트에 관한 문헌 연구들은 크게 성장하고 있지만, 동인과 결과에 대한 경험적인 연구는 제한적이다(Ledke, Nyadzayo, \& Johnson, 2016; Touni, Km Choi, \& Ali, 2020). 본 연구에서는 고객 인게이즈먼트의 선행요인으로 소비자 내적 상태인 소비자 관여도와 외부 자극 요소인 상대적 이점을 제안한다.

이를 위해 본 연구에서는 외식업계의 주 고객층의 역할을 하게 될 MZ 세대들을 대상으로 외식업 서비스에 대한 개인적인 관여도와 $\mathrm{O} 2 \mathrm{O}$ 기반 혁신 서비스의 이점에 따라, 인지적, 정서적인 인게이즈먼트를 통해 충성도로 이어지는가를 알아보고자 한다. 이를 알아보기 위하여 $\mathrm{MZ}$ 세대들이 쉽게 접근할 수 있는 햄버거 프랜차이즈 이용 소비자 중, 요식업 관련 앱을 사용해본 경험자를 대상으로 혁신서비스에 대한 소비자 태도, 충성도 관계 연구를 진행하였다. 이를 통해 혁신과 소비자관련 연구의 다양성을 넓히고, 실무적으로는 프랜차이즈 기업들이 한정된 자원을 가지고 표적고객에 혜택 전달과 지속적인 관계를 이끌 수 있는 영역에 투자를 위한 전략을 수립할 수 있는 시사점을 제시하고자 한다. 


\section{2. 이론적 고찰}

\section{1. 관여도}

관여도(Involvement)는 내재적 요구, 가치와 관심에 기초한 개인의 인식된 관련성 또는 중요성을 말한다(Zaichkowsky, 1985). 소비자의 개인적 관여도는 자극에 대한 개인적 반응을 결정하는 개인의 내부 각성 상태로도 설명된다(Leung \& Bai, 2013). Zaichkowsky(1994)는 소비자가 상품, 광고와 같은 외부적 자극에 관여될 수 있다고 언급하였다. $\mathrm{O} 2 \mathrm{O}$ 서비스는 하나의 자극이기 때문에, $\mathrm{O} 2 \mathrm{O}$ 서비스에 대한 소비자의 관여도는 고객 인게이즈먼트의 중요한 예측 요인이다.

관여도를 가진 소비자는 보다 깊은 정보처리(Bumkrant \& Samyer, 1983), 높은 정교화P(Petty \& Cacioppo, 1986)와 좀더 많은 제품 시도(Knugman, 1965; Robertson, 1976)를 실시한다. 따라서 관여도는 특정 관여 행위 이전에 브랜드에 대한 관심과 개인적 관여도를 가진 고객의 브랜드 참여의 선행요인이 될 수 있다(Zaichkowsky, 1985).

관여도는 3 가지 유형으로 식별될 수 있다: 1) 특정 상황에서 상황적 관여도가 발생, 2) 대상과 관련된 본질적이고 지속적인 관심과 관련된 지속적 관여 3) 반응관여는 의사결정과정의 확장(Bloch \& Richins, 1983; Zaichkowsky, 1985). 본 연구에서는 패스트푸드 이용과 연결된 소비자 개인의 관심과 관여로 정의하였다

\section{2. 상대적 이점}

상대적 이점(Relative advantages)은 혁신이 기존 것보다 우수하다"고 인식되는 정도를 말한다(Moore \& Benbasat, 1991). 혁신확산이론에서 Rogers (2010)는 상대적 이점은 대체할 수 있는 아이디어보다 혁신이 더 낫다고 인식되는 정도로써 주요 혁신 속성이며, 혁신 채택 정도를 예측하기 위한 최상의 지표로 정의하였다. 상대적 이점이 새로운 제품 및 서비스가 기존 제품 및 서비스에 비해 상대적으로 우월한 것인지 여부를 나타내는 차원에서 기술수용모델(TAM)의 인지된 유용성(perceived usefulness)와 유사한 개념으로 새로운 기술을 채택하려는 의도를 높이는데 도움이 된다(Wang, Meister, \& Wang, 2011).

Schiffman and Kanuk(1991)은 혁신제품이 기존 제품과 비교하여 기능이나 성능이 우수하다고 소비자들이 인지한다면 이용자 만족도가 높아질 것이라고 주장하였다. Bae(2018)는 인터넷 전문은행의 상대적 이점이 이용자 만족도에 긍정적 영향을 미치는 것을 검증했다. 본 연구에서 상대적 이점은 패스트푸드의 O2O 기반 혁신 서비스의 독특한 혜택과 타사 대비 이점을 제공한다고 인식하는 정도로 정의된다.

\section{3. 고객 브랜드 인게이즈먼트}

고객 브랜드 인게이즈먼트(Consumer brand engagement)는 주요 소비자/브랜드 상호 작용 중 또는 이와 관련되어 소비자의 긍정적인 인지, 정서, 행위로 정의(Hollebeek, Glynn, \& Brodie, 2014)되며, 참여 주체와 참여 대상 간에 상호작용과 이어지는 경험을 기반으로 한다(Dwivedi, 2015; L Hollebeek, 2011a; Hollebeek, 2011b). 최근 연구에서는 고객 브랜드 인게이즈먼트의 다차원적 특성이 강조되고 있으며, 일반적으로는 인지적, 감정적, 행동적 차원으로 구성된다(Dwivedi, 2015; Linda D. Hollebeek et al, 2014; Leventhal, Hollebeek, \& Chen, 2014). 이러한 차원의 상대적 중요도는 상황에 따라 다를 수 있다Brodie, Hollebeek, Junć, \& licí 2011).

Linda D. Hollebeek et al. (2014)은 인게이즈먼트 대상과 전체적인 상호작용과 관련하여 인지적, 감정적, 행동적 활동을 고객 브랜드 인게이즈먼트로 특성화하고 측정을 위한 척도를 구성했다. 인지적 인게이즈먼트는 특정 소비자/브랜드 상호작용에 있어 소비자의 브랜드관련 사고 처리와 정교화 수준, 정서적 엔게이즈먼트는 특정 소비자/브랜드 상호작용에 있어 소비자의 브랜드관련 긍정적 애정의 정도 그리고 활성화행동적) 엔게이즈먼트는 특정 소비자/브랜드 상호작용에 있어 소비자가 브랜드에 쏟는 에너지, 노력과 시간의 정도를 말한다.

본 연구에서는 패스트푸드서비스와 고객의 상호작용 중 인지적, 정서적 차원의 인게이즈먼트가 충성도에 미치는 영향을 살펴보고자, 인지적 인게이즈먼트는 패스트푸드 서비스 이용 시 브랜드 정보처리, 정서적 인게이즈먼트는 패스트푸드 서비스와 관련된 긍정적 감정의 정도로 정의하였다.

\section{4. 충성도}

Oliver(1997)는 고객 충성도를 상황적 영향과 전환 행동을 일으킬 수 있는 잠재적 마케팅 노력에도 불구하고 미래에 지속적으로 선호하는 상품과 서비스를 재구매하고 다시 애용하겠다는 깊은 약속으로 정의하였다. 최근 연구는 충성도를 반복 구매 행동으로 이어지는 서비스 조직에 대한 고객의 유리한 태도로 정의한다Ledke, Nyadzayo, \& Johnson, 2018; Sinivasan, Anderson, \& Ponnavolu, 2002).

제품 또는 서비스를 좋아하고 싫어하는 정서적 충성도는 제품 속성이 아닌 제품에 대한 긍정적 성향을 반영하며(Evanschittky \& Wunderlich, 2006, 행동적 구성 요소는 인지적 또는 정서적 요소에 의해 결정된 고객의 재구매 의도를 나타낸다(Badk, 2005). 본 연구에서 충성도는 인지적 감정적 측면의 인게이즈먼트와 차별화된 개념으로 행동적 
구성요소로 미래에 해당 패스트푸드 매장 이용 의사에 대한 평가로 정의되었다.

\section{3. 연구설계}

\section{1. 연구가설}

\subsection{1. 관여도와 인지적, 정서적 인게이즈먼트 관계}

관여도의 개념은 고객 브랜드 참여의 필수 선행자로써 주목을 받고 있다(Dwivedi, 2015). 소비자의 동기는 관련성을 느끼는 정도에 따라 증가한다. 만약 대상(예, 브랜드)가 소비자와 관련이 있다면, 소비자는 대상과 관련된 상황 분석에 인지적 노력을 기울이고, 더욱 자세하게 그것을 분석할 가능성이 높다(Celsi \& Olson, 1988; Greenwald \& Leavitt, 1984). 소비자는 대상과 관련된 정보에 관심을 기울이기 때문에 대상관련 생각과 추론은 전반적으로 증가한다(Celsi \& Olson, 1988)

감정은 사건이나 개인의 생각의 인지적 평가에서 발생한다(Bagozi, Gopinath, \& Nyer, 1999; Smith \& Elsworth, 1985). 감정적 반응이 일어나기 위해서는 상황은 반드시 소비자와 관련이 있어야 하며(Bagozj et al, 1999), 사건의 결과가 소비자의 욕구 또는 요구와 일치하면, 높은 개인적 관여도를 가진 소비자에게 강한 긍정적 감정이 일어난다(Nyer, 1997).

과거 연구들은 관심이나 관여도가 높은 소비자는 인게이즈먼트가 강회될 가능성이 높다고 하였다(Hamigan, Evers, Miles, \& Daly, 2018; Hepola, Kajjaluoto, \& Hintikka, 2017; Vivek, Beatty, \& Morgan, 2012). Hollebeek(2014)는 고객 브랜드 관여도가 고객 브랜드 인게이즈먼트의 하위 차원(인지처리, 애정 및 활성화)에 긍정적인 영향을 미친다는 것을 발견했다.

따라서 선행연구를 바탕으로 관여도와 인지적, 정서적 인게이즈먼트의 관계를 다음과 같은 가설들이 제시되었다.

H1: 관여도는 인지적 인게이즈먼트에 정(+)의 영향을 미칠 것이다. H2: 관여도는 정서적 인게이즈먼트에 정(+)의 영향을 미칠 것이다.

\subsection{2 상대적 이점과 인지적, 정서적 인게이즈먼트 관계}

사회적 교환 이론(social exchange theory)에 의하면, 비용이 기대되는 혜택보다 크면 다른 당사자들과 관계를 맺고 유지한다고 주장한다(Blau, 1964; Foa \& Foa, 1980). 반면 Agarwal and Prasad (1998)는 새로운 서비스가 기존의 대안보다 더 나은 것으로 인식되면, 고객은 대중 매체를 통해 더 많이 알게 될 것이라고 주장하였다. Mende, Thompson, and Coenen (2015)는 고객이 기존 은행의 서비스가 경쟁사보다 우수한 혜택을 제공한다는 것을 알게 되면 입소문 의사 소통에 참여할 가능성이
높다는 것을 발견했다. 또한 Ledkie et al.(2018)은 Uber 서비스에 대한 상대적 이점이 고객 브랜드 인게이즈먼트의 한 형태의 브랜드 정보 수집과 마케팅 활동 참여에 긍정적인 영향을 미치는 것을 검증하였다.

따라서 선행연구를 바탕으로 상대적 이점과 인지적, 정서적 인게이즈먼트의 관계를 다음과 같은 가설들이 제시되었다.

H3: 상대적 이점은 인지적 인게이즈먼트에 정(+)의 영향을 미칠 것이다. H4: 상대적 이점은 정서적 인게이즈먼트에 정(+)의 영향을 미칠 것이다.

\subsection{3 인지적, 정서적 인게이즈먼트와 점포 충성도 관계}

고객 브랜드 인게이즈먼트는 필연적으로 브랜드와 소비자의 강한 유대를 반영하는 관계형 구조이며, 소비자에게 긍정적이고 만족스러운 보람 있는 경험을 나타낸다(Dwivedi, 2015). 고객의 브랜드 경험이 긍정적 인 경우, 자신의 기억에 저장되며 만족도와 충성도에 영향을 미칩니다 (Brodie, Ilic, Juric, \& Hollebeek, 2013; Oliver, 1997). Kunz et al. (2011)는 혁신에 대한 광범위한 소비자 중심의 관점 연구에서, 인지적 관점의 만족도가 감정적 관점의 만족도의 영향관계를 밝혀냈다.

또한 고객 브랜드 인게이즈먼트의 계층적 개념은 충성도와 매우 관련이 있다(Oliver, 1997). Oliver (1997)는 충성도에는 태도와 행위적/행동 단계와 태도 단계에는 3 가지 주요 단계(예, 인지, 정서, 능동)가 있다고 주장했다. 이러한 서로 다른 충성도 단계는 동시가 아니라 연속적으로 나타나며 (Evanschittky \& Wunderlich, 2006; Oliver, 1997), 참여 소비자는 초점 브랜드에 대한 강한 신념을 개발하고, 감정을 강화하여 반복적인 구매 행동을 수행할 가능성이 더 높다 (Back \& Parks, 2003; Han, Km, \& Kim, 2011; R L Oliver, 1999; Vivek et al, 2012).

특히 고객의 충성도는 인지적, 정서적, 능동적, 행동적/행동의 단계를 통해 증가한다. Hamigan, Evers, Miles, and Daly (2018)는 소비자는 정보를 처리하여 신념을 형성하고, 그러한 신념을 사용하여 태도를 형성하여 행위적 활동으로 발현되는 과정을 소셜 미디어상의 인게이즈먼트와 브랜드 사용의도에서 검증하였다.

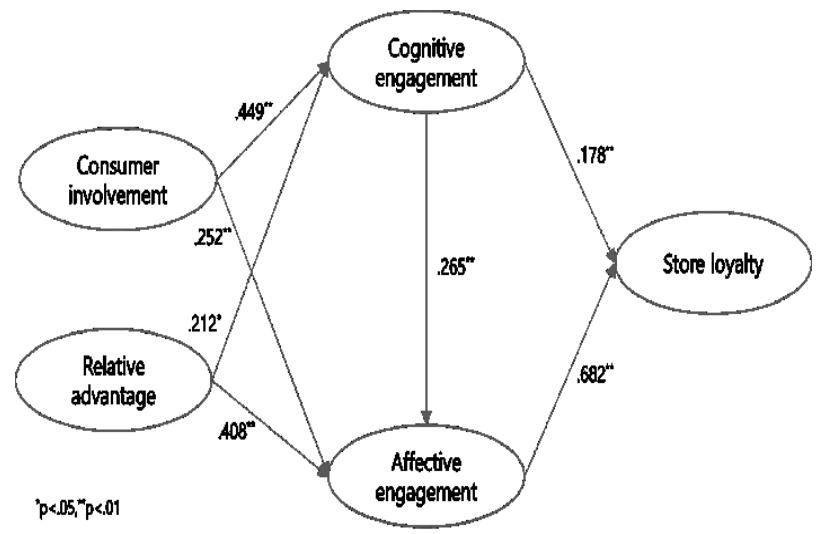

Figure 2 : The estimated structural model 
따라서 선행연구를 바탕으로 인지적, 정서적 인게이즈먼트와 점포 충성도의 관계를 다음과 같은 가설들이 제시되었다.

H5: 인지적 인게이즈먼트는 정서적 인게이즈먼트에 정(+)의 영향을 미칠 것이다.

H6: 인지적 인게이즈먼트에 점포 충성도에 정(+)의 영향을 미칠 것이다. H7: 정서적 인게이즈먼트는 점포 충성도에 정(+)의 영향을 미칠 것이다.

\section{4. 실증분석}

\section{1. 표본설계 및 분석방법}

본 연구에서는 연구가설을 검증하기 위하여 패스트푸드, 커피, 음식배달 앱을 이용한 경험이 있는 10-30 대 MZ 세대 소비자들을 대상으로 온라인 설문조사를 실시하였으며, 총 247 개의 표본이 이용되었다. 본 연구의 주제인 패스트푸드 $\mathrm{O} 2 \mathrm{O}$ 서비스에 대한 상대적 이점과 관여도를 측정하기 위해서, 유사 $\mathrm{O} 2 \mathrm{O}$ 서비스 경험을 바탕으로 패스트푸드 $\mathrm{O} 2 \mathrm{O}$ 서비스의 상대적 이점을 판단할 수 있는 요식업 $\mathrm{O} 2 \mathrm{O}$ 서비스 이용자로 설문 대상을 한정하였다.

가설 검증 및 해석을 위한 분석 과정은 두 단계로 진행되었다. 먼저, 측정모형 분석을 통하여 연구단위의 타당성과 신뢰성, 공통방법편의가 검증되었다. 다음으로, 연구모형 및 가설의 인과관계를 검증하기 위하여 SmartPLS 3.0 을 이용한 구조모형분석이 실시되었다.

\section{2. 표본의 일반적 특성}

본 연구의 응답자(247 명)에 대한 일반적 특성은 Table 1 과 같다. 먼저, 성별은 남성이 30\%로 여성(70\%)보다 많았으며, 만 16 세부터 23 세에 해당하는 Z 세대가 52\%, 만 24 세부터 39 세까지 M 세대가 48\%를 차지했다. 직업은 학생 $47 \%$, 직장인은 $38 \%$ 를 차지했다. 자주 이용하는 패스트푸드 브랜드는 맥도날드(33\%), 맘스터치(32\%)가 65\%로 나타났고, 주 1 회 이상 햄버거 패스트푸드를 이용하는 응답자가 $71 \%$ 를 차지했다.

Table 2: Demographic Profiles $(n=247)$

\begin{tabular}{|c|c|c|c|}
\hline \multirow{2}{*}{ Gender } & Category & Frequency & $\%$ \\
\cline { 2 - 4 } & Male & 73 & 30 \\
\hline \multirow{2}{*}{ Generation } & Female & 174 & 70 \\
\cline { 2 - 4 } & Z (1997 2004) & 129 & 52 \\
\cline { 2 - 4 } & Millennials (1981 1996) & 118 & 48 \\
\hline
\end{tabular}

\begin{tabular}{|c|c|c|c|}
\hline \multirow{7}{*}{ Job } & Student & 115 & 47 \\
\hline & Office & 72 & 29 \\
\hline & Professional & 13 & 5 \\
\hline & Self-employment & 5 & 2 \\
\hline & HouseKeeper & 9 & 4 \\
\hline & Inoccupation(Preparing) & 30 & 12 \\
\hline & Etc. & 3 & 1 \\
\hline \multirow{5}{*}{$\begin{array}{l}\text { Frequently } \\
\text { visitd fast food } \\
\text { brand }\end{array}$} & Lotteria & 41 & 17 \\
\hline & Macdonald & 81 & 33 \\
\hline & BurgerKing & 44 & 18 \\
\hline & Momstouch & 79 & 32 \\
\hline & KFC & 2 & 1 \\
\hline \multirow{5}{*}{$\begin{array}{l}\text { Freqeuncy of } \\
\text { visit }\end{array}$} & Almost everyday & 6 & 2 \\
\hline & 4 5 times a week & 20 & 8 \\
\hline & 2 3 times a week & 64 & 26 \\
\hline & Once a week & 86 & 35 \\
\hline & 1 2 a month & 71 & 29 \\
\hline
\end{tabular}

\section{3. 측정항목의 타당성 및 신뢰성 검증}

본 연구에서는 다항목으로 구성된 연구단위의 단일차원성을 분석하기 위하여 SmartPLS 3.0 을 이용하였다(Hair Jr, Hult, Ringle, \& Sarstedt, 2016; Kim, Kim, \& Lee, 2019).

먼저, 연구 대상의 내적 일관성을 측정하는 신뢰성은 Cronbach's $\alpha$ 와 연구단위 신뢰도(composite reliability. CR)을 이용하여 분석되었다, 각 연구단위들에 대한 Cronbach's $\alpha$ 값은 830-912, CR 값은 898-934로 요구 기준인 .70을 넘어 측정 항목 간 신뢰성이 있는 것으로 나타났다.

다음으로, 개념 타당성을 측정하기 위해 수렴 타당성과 판별 타당성으로 구분하여 검증하였다. 수렴타당성은 동일한 개념 간의 높은 상관관계로 평가되는데 그 결과, 요인에 적재된 요인 적재값은 786 이상이며, AVE 값이 .741 이상으로 나타나 각 연구단위의 수렴 타당성은 입증되었다(Appendix 1 Refer).

판별 타당성은 상이한 개념 간의 낮은 상관관계로 평가되는데, Formell-Larcker 기준으로 검증한 결과, AVE 값의 제곱근 값이 상관관계 계수 값보다 크며, 쌍을 이룬 연구단위 간의 상관관계 값의 자승 값이 $\mathrm{AVE}$ 값보다 작은 것으로 나타나 각 연구단위 간의 판별 타당성은 입증되었다. 또한, 상관계수 값의 이질성·단질성 특성 비율을 나타내는 HTMT(the heterotrait-monotrait) 값을 살펴본 결과, $509-795(\mathrm{p}<.01)$ 로 나타나 판별 타당성은 입증되었다. 한편, 공통방법편의는 
분산팽창요인(variance inflation factor. VIF)이 33 보다 작은 것(1.5982123)으로 나타나 문제가 되지 않았다(Appendix 2 Refer).

\section{4. 연구모형의 평가}

본 연구는 SmartPLS 3.0 을 사용하여 연구모형을 평가하였다. PLS 는 분산설명력의 최대화 또는 구조오차를 최소화하기 위한 연구에 적합한 분석 방법으로 다음과 같이 평가되었다(Tenenhaus, Vinzi, Chatelin, \& Lauro, 2005; Hur, Nor, \& Lee, 2019).

먼저, 설명력과 예측적합도를 다음과 같이 평가하였다. 첫째, 전술한 바와 같이, 분산팽창요인(variance inflation factor. VIF)이 1.598-2.123 으로 5 보다 작은 것으로 나타나 다중공선성 문제가 없는 것으로 나타났다. 둘째, 예측적합도 판정을 위해 내생변수의 설명력을 나타내는 결정계수인 $\mathrm{R}^{2}$ 값을 사용하는데, 본 영구에서 $\mathrm{R}^{2}$ 값은 인지적 인게이즈먼트는 $0295(29.5 \%)$, 정서적 인게이즈먼트가 $0.485(48.5 \%)$, 행동 인게이즈먼트는 0.328(32.8\%), 상점 충성도는 0.585(58.5\%)로 Falk and Miller (1992) 제시한 100(10\%)보다 높게 나타났다. Chin (1998)은 설명력 크기의 기준을 .67(강), 33(중), 19(약)로 제시하였다. 셋째, 예측적합도를 판단하기 위해 사용하는 내생변수의 중복성을 나타내는 연구단위 교차 타당성의 중복성(construct cross-validated redundancy. Q)값은 0 보다 크면 예측적합도가 있는 것으로 판단된다. 본 연구에서는 인지적 인게이즈먼트가 295 , 정서적 인게이즈먼트가 485 , 행동 인게이즈먼트가 328 , 상점 충성도가 585 로 나타나 예측적합도의 기준을 충족시켰다. 그리고 SRMR(the standardized root mean residual)이 0.91 로 기준치인 1 보다 작은 것으로 나타나 모형의 예측력이 좋은 것으로 나타났다(Appendix 3 Refer).

\section{5. 연구가설의 검정}

구조모형 분석 결과는 다음과 같다.

$\mathrm{H} 1, \mathrm{H} 2$ 는 관여도가 인지적, 정서적 인게이즈먼트에 미치는 영향관계를 설명하기 위한 것이다. 분석 결과, 인지적 인게이즈먼트 $(\beta=394, t$-value $=4.733, \quad p<.01)$ 과 정서적 인게이즈먼트 $(\beta=269, \mathrm{t}-\mathrm{value}=3.622, \mathrm{p}<.01)$ 모두에 유의한 정(+)의 영향을 미치는 것으로 나타나, $\mathrm{H} 1$ 와 $\mathrm{H} 2$ 는 지지가 되었다.

$\mathrm{H} 3, \mathrm{HA}$ 는 상대적 이점이 인지적, 정서적 인게이즈먼트에 미치는 영향관계를 설명하기 위한 것이다. 분석 결과, 인지적 인게이즈먼트 $(\beta=206, t$-value $=2447, p<.01)$ 와 정서적 인게이즈먼트 $(\beta=368, t-v a l u e=5201, p<.01)$ 모두에 유의한 정(+)의 영향을 미치는 것으로 나타나, $\mathrm{H} 3$ 과 $\mathrm{H} 4$ 는 지지가 되었다.
$\mathrm{H} 5$ 은 인지적 인게이즈먼트가 정서적 인게이즈먼트에 미치는 영향관계를 설명하기 위한 것이다. 분석 결과, 정서적 인게이즈먼트 $(\beta=234, t-v a l u e=3.452, p<.01)$ 에 유의한 정( + )의 영향을 미치는 것으로 나타나, $\mathrm{H} 5$ 는 지지가 되었다(Appendix 3 Refer).

$\mathrm{H} 6$ 은 인지적 인게이즈먼트가 충성도에 미치는 영향관계를 설명하기 위한 것이다. 분석 결과, 충성도 $(\beta=201, \mathrm{t}-\mathrm{value}=3.070, \mathrm{p}<.01)$ 에 유의한 정(+)의 영향을 미치는 것으로 나타나, $\mathrm{H6}$ 은 지지가 되었다.

$\mathrm{H} 7$ 은 정서적 인게이즈먼트가 충성도에 미치는 영향관계를 설명하기 위한 것이다. 분석 결과, 충성도 ( $\beta=595, \mathrm{t}-\mathrm{value}=10.018, \mathrm{p}<.01)$ 에 유의한 정(+)의 영향을 미치는 것으로 나타나, $\mathrm{H} 7$ 은 지지가 되었다.

\section{5. 결론}

\section{1. 연구결과의 요약 및 시사점}

본 연구에서는 패스트푸드 외식 프랜차이즈 기업이 O2O 기반 서비스 전략을 수립하기 위해 MZ 세대를 대상으로 고객이 인지하는 상대적 이점과 관여도가 브랜드 인게이즈먼트에 미치는 영향을 파악하고 이러한 인지적, 정서적 인게이즈먼트가 충성도에 미치는 영향을 연구하였고, 그 시사점은 다음과 같다.

첫째, 관여도는 인지적 인게이즈먼트와 정서적 인게이즈먼트 모두에 긍정적 영향을 미치며, 앞서 제시한 가설을 지지함으로써 관여도는 고객 브랜드 인게이즈먼트의 예측 변수임이 검증되었다(Bowden, 2009; Hollebeek, 2011a). 각각의 영향도를 살펴보면, 관여도가 정서적 인게이즈먼트에 비해 인지적 인게이즈먼트에 좀 더 강한 영향을 주고 있음을 알 수 있다. 이는 패스트푸드를 이용하는 것에 관련도를 높게 느끼는 소비자들은 패스트푸드 이용을 통해 긍정적 감정을 느끼기 이전에 관여도가 동기수준을 증가시키고(Bloch, Shemell, \& Ridgway, 1986; Zaichkowsky, 1985) 정교화 수준이 올라감에 따라, 순차적으로 상호작용 과정에서 브랜드를 쉽게 인지 및 정보 호기심이 커진다는 것을 알 수 있다. 이러한 결과는 관여도가 높은 고객들은 블로그, 유튜브 등 SNS을 통해 스스로 정보를 검색하는 인지적 상호작용에 참여할 가능성이 높고, 이를 통해 긍정적 감정을 유도할 수 있다는 시사점을 제공해준다.

둘째, 상대적 이점은 제시한 가설과 같이 인지적과 정서적 인게이즈먼트 모두에 긍정적 영향을 미치는 것으로 나타났다. 각각의 영향도를 살펴보면, 상대적 이점은 관여도와 반대로 인지적 인게이즈먼트보다는 정서적 인게이즈먼트에 더 높은 설명력을 가지는 것으로 나타났다. 이는 상대적 이점이 인지적 처리보다 감정적 처리로 빠르게 전이될 수 있도록 정서적 측면의 전달력이 높은 컨텐츠 제작이 되어야 한다는 것을 시사한다. 기존 외식 프랜차이즈 기업의 SNS 
마케팅 활동 연구 정보를 통해 쾌락적 가치와 실용적 가치 전달로 소비자 행동의도에 긍정적 영향을 미치는 것이 밝혀진 바(Lee et al, 2019) 같이, 온라인 소통을 선호하는 MZ 세대들에게는 SNS 을 통해 경쟁사 대비 고객에게 제공하는 가치를 전달하는 노력이 필요하다. 기존 프랜차이즈 고객 대상으로 M 세대의 소비성향 연구(Roh, et al, 2020)를 참조하였을 때, 빠른 욕구 충족, 가성비, 경제성과 같은 강점을 부각한다면 긍정적 정서를 형성할 가능성이 높다셋째, 인지적 인게이즈먼트가 정서적 인게이즈먼트에 긍정적 영향을 보여주며, 충성도에는 미치는 영향은 정서적 인게이즈먼트가 인지적 인게이즈먼트보다 강하게 나타났다. 이는 고객 인게이즈먼트는 충성도의 선행 요인으로 충성도 형성단계를 따라 참여과정 중 인지적 단계, 정서적 단계와 이를 통한 행동 단계로 순차적으로 이루짐에 따라, 정서적 인게이즈먼트가 충성도에 좀더 높은 설명력을 가진다는 것을 의미한다. 따라서 인게이즈먼트의 단계별 흐름과 관계를 이해하고 고객과 상호작용 전략수립이 필요하다는 점을 보여준다.

전체적으로 평소 패스트푸드에 높은 관여도를 느끼고 있는 젊은 고객들은 브랜드 관련된 정보에 높은 관심을 가지며, 소비자 인게이즈먼트의 초기 단계로 브랜드관련 사고를 활성화함으로써 인지적 투자가 크다고 할 수 있다. 또한 우수한 상대적 이점을 인식한 고객은 브랜드와 상호작용에 정서적 투자를 할 가능성이 높으며, 사회교환이론에 따르면 이러한 소비자들의 투자는 지속적으로 더 많은 혜택을 얻기 위해 브랜드와 상호작용 관계를 유지할 가능성이 더 높다는 것을 보여준다(Blau, 1964; Foa \& Foa, 1980). 따라서 충성도에 미치는 영향을 평가할 때, 소비자/브랜드 상호작용 중 소비자의 정서적 활동을 높이는 것이 상대적으로 효과가 크다고 할 수 있다.

그러나 인지적 인게이즈먼트가 충성도에 미치는 영향은 정서적 인게이즈먼트에 비해 상대적으로 작지만, 높은 관여도를 가지는 고객의 인지적 인게이즈먼트와 강한 연관 관계를 고려할 때, 패스트푸드 외식을 중요하게 생각하는 젊은 고객들에게는 인지적 측면 상호작용도 또한 중요하다 할 수 있다. 온라인 소통을 선호하고 소속감과 친밀감을 형성하는 MZ세대 고객과의 디지털 연결을 위해 유튜브 등을 통해 매장 정보, 브랜드 소식, 궁금증 해소 등 다양한 콘텐츠를 전달함으로써 유대감을 강화는 것이 효과적일 것이다.

따라서 패스트푸드 외식 프랜차이즈 기업의 $\mathrm{O} 2 \mathrm{O}$ 서비스 전략을 수립함에 있어, 언택트 니즈가 높은 $\mathrm{MZ}$ 세대의 특성을 고려하여 관여도를 높게 생각하는 고객들과 정보차원의 상호작용을 높일 수 있는 온라인 의사소통 채널을 확보하고 정기적인 정보제공 등의 노력을 통해 장기적인 충성고객으로 유지가 필요하며, 전반적으로는 서비스가 경쟁사와의 차별화된 이점의 효과적인 전달을 통해 고객의 정서적 측면의 인게이즈먼트를 높임으로써 참여 행동을 유발하고, 긍정적 경험을 통해 충성도를 확보하는 것이 필요하다. 예를 들면, 셀프서비스, 푸드로봇 등 기술기반 매장내 언택트서비스 도입에 있어서도 신속한
도입으로 대면서비스 불안감 해소 및 식품 안전에 대한 상대적 이점을 효과적으로 고객에게 전달한다면, 고객 충성도를 높임으로써 점주의 수익 향상과 더불어 장기적으로 프랜차이즈 기업 경쟁력 향상에 기여할 것이다.

\section{2. 연구의 한계 및 향후 연구 과제}

본 연구는 소비재 시장의 주 소비층으로 중요도가 커지는 MZ세대를 대상으로 햄버거 패스트푸드 프랜차이즈 서비스의 상대적 이점과 관여도가 충성도에 어떠한 영향을 미치는지를 구조적 인과관계로 실증하였다. 관여도, 상대적 이점이 고객 인게이즈먼트 단계별로 미치는 영향을 확인함으로써 외식 프랜차이즈 기업에게 고객 인게이즈먼트 관리의 중요성에 대한 유의미한 시사점을 제공할 것으로 기대할 수 있다. 그럼에도 불구하고 본 연구는 다음과 같은 한계점이 있으며, 이에 따라 앞으로 연구방향을 제시하면 다음과 같다.

첫째, 본 연구의 설문조사는 요식업 $\mathrm{O} 2 \mathrm{O}$ 서비스를 이용해본 $\mathrm{MZ}$ 세대를 대상으로 진행되어 표본의 대표성에 한계가 있다. 향후 연구는 $\mathrm{NZ}$ 세대가 기존세대와 가지는 차이점을 파악하기 위해 좀 더 다양한 연령층의 응답을 확보한다면 보다 정확하고 의미 있는 결과를 얻을 수 있을 것으로 본다. 또한 $\mathrm{O} 2 \mathrm{O}$ 서비스를 이용하지 않은 소비자를 대상으로 FG 및 사용 후 변화된 태도를 조사한다면, O2O 서비스를 사용하지 않는 이유를 파악하고, 해당 서비스를 사용하였을 때 어떤 부분의 이점을 중요하게 인지하는지 판단할 수 있을 것이다. 이를 통해 $\mathrm{O} 2 \mathrm{O}$ 서비스 사용자 확대를 위한 전략에 도움이 될 것이다.

둘째, 소비자의 혁신성, 소비성향 등 개인의 관여도에 영향을 미칠 수 있는 응답자 개인적인 특징을 선행변수로 다룸으로써 관여도가 높은 소비자군의 특징을 알아내면, 프랜차이즈 기업의 고객 세분화에 따른 소통전략을 수립에 좀더 실무적인 시사점을 제공할 수 있을 것이다.

셋째, 혁신 유형별로 상대적 이점의 하위요소인 다양한 가치요인들을 함께 분석한다면, 요식업 프랜차이즈 기업이 제공하는 서비스에 대한 소비자 가치인식과의 관계를 더욱 정밀하게 분석할 수 있을 것이다. 이를 통해 프랜차이즈 기업은 디지털 트랜스포메이션을 위한 다양한 혁신 시도 중에 좀더 효과적으로 고객에게 이익을 제공할 수 있는 서비스를 기획할 수 있을 것으로 기대된다.

\section{References}

Avnet, T., \& Higgins, E. T. (2006). How regulatory fit affects value in consumer choices and opinions. Journal of Marketing Research, 43(1), 1-10.

Back, K.-J. (2005). The effects of image congruence on customers' brand loyalty in the upper middle-class hotel industry. Journal of Hospitality \& Tourism Research, 29(4), 448-467. 
Back, K.-J., \& Parks, S. C. (2003). A brand loyalty model involving cognitive, affective, and conative brand loyalty and customer satisfaction. Journal of Hospitality \& Tourism Research, 27(4), 419-435

Bae, J. K. (2018). A study on the effect of personal innovativeness, perceived relative advantage, rerceived serviceability, and perceived security on satisfaction and continuance usage Intention in internet primary bank users. Logos Management Review, 16(4), 141-154.

Bagozzi, R. P., Gopinath, M., \& Nyer, P. U. (1999). The role of emotions in marketing. Journal of the Academy of Marketing Science, 27(2), 184-206.

Blau, P. M. (1964). Exchange and power in social life. New York: John Wiley and Sons. In: Inc.

Bloch, P. H., \& Richins, M. L. (1983). A theoretical model for the study of product importance perceptions. Journal of Marketing, 47(3), 69-81.

Bloch, P. H., Sherrell, D. L., \& Ridgway, N. M. (1986). Consumer search: An extended framework. Journal of Consumer Research, 13(1), 119-126.

Bowden, J. L.-H. (2009). The process of customer engagement: A conceptual framework. Journal of Marketing Theory and Practice, 17(1), 63-74.

Brodie, R. J., Hollebeek, L. D., Jurić, B., \& Ilić, A. (2011). Customer engagement: Conceptual domain, fundamental propositions, and implications for research. Journal of Service Research, 14(3), 252-271.

Brodie, R. J., Ilic, A., Juric, B., \& Hollebeek, L. (2013). Consumer engagement in a virtual brand community: An exploratory analysis. Journal of Business Research, 66(1), 105-114.

Burnkrant, R. E., \& Sawyer, A. G. (1983). Effects of involvement and message content on information-processing intensity. Information Processing Research in Advertising, 12(2), 46-64.

Byun, J.-W. (2019). The effects of perceived relationship benefits of customer using kiosk on customer feeling and continuous intention: Focused on consumers of fast food restaurants. Journal of Foodservice Management Society of Korea, 22, $187-212$.

Celsi, R. L., \& Olson, J. C. (1988). The role of involvement in attention and comprehension processes. Journal of Consumer Research, 15(2), 210-224.

Cha, S. S, \& Seo, B. K. (2020). The effect of food delivery application on Customer Loyalty in Restaurant. Journal of Distribution Science, 18(4), 5-12.

Cha, S. S., \& Shin, M . H. (2019). Influence of O2O service usability and reliability on purchase intention: Focusing on smart orders. Journal of Distribution and Management Research, 22(5), 21-29.

Chin, W. W. (1998). The partial least squares approach to structural equation modeling. Modern Methods for Business Research, 295(2), 295-336.

Dwivedi, A. (2015). A higher-order model of consumer brand engagement and its impact on loyalty intentions. Journal of Retailing and Consumer Services, 24, 100-109.

Evanschitzky, H., \& Wunderlich, M. (2006). An examination of moderator effects in the four-stage loyalty model. Journal of Service Research, 8(4), 330-345.

Falk, R. F., \& Miller, N. B. (1992). A primer for soft modeling: University of Akron Press.
Foa, E. B., \& Foa, U. G. (1980). Resource theory. In Social exchange (pp. 77-94): Springer.

Greenwald, A. G., \& Leavitt, C. (1984). Audience involvement in advertising: Four levels. Journal of Consumer Research, 11(1), 581-592.

Hair Jr, J. F., Hult, G. T. M., Ringle, C., \& Sarstedt, M. (2016). A primer on partial least squares structural equation modeling (PLS-SEM): Sage Publications.

Han, H., Kim, Y., \& Kim, E.-K. (2011). Cognitive, affective, conative, and action loyalty: Testing the impact of inertia. International Journal of Hospitality Management, 30(4), 1008-1019.

Harrigan, P., Evers, U., Miles, M. P., \& Daly, T. (2018). Customer engagement and the relationship between involvement, engagement, self-brand connection and brand usage intent. Journal of Business Research, 88, 388-396.

Hepola, J., Karjaluoto, H., \& Hintikka, A. (2017). The effect of sensory brand experience and involvement on brand equity directly and indirectly through consumer brand engagement. Journal of Product \& Brand Management, 26(3), 282-293.

Hollebeek, L. (2011a). Exploring customer brand engagement: Definition and themes. Journal of Strategic Marketing, 19(7), 555-573.

Hollebeek, L. D. (2011b). Demystifying customer brand engagement: Exploring the loyalty nexus. Journal of Marketing Management, 27(7-8), 785-807.

Hollebeek, L. D., Glynn, M. S., \& Brodie, R. J. (2014). Consumer brand engagement in social media: Conceptualization, scale development and validation. Journal of Interactive Marketing, 28(2), 149-165.

Hollebeek, L. D., Srivastava, R. K., \& Chen, T. (2019). SD logicinformed customer engagement: Integrative framework, revised fundamental propositions, and application to CRM. Journal of the Academy of Marketing Science, 47(1), 161-185.

Hur, S.-B., Nor, Y.-S., \& Lee, D. (2019). The Impact of franchisor's economic and philanthropic CSR on franchisees' economic satisfaction, social satisfaction, and loyalty. Korean Journal of Franchise Management, 10(3), 25-35.

Hwang, Sung-Won, \& Kim, Hyun-Suk (2019). A study on the user experience of unmanned order payment kiosk in fast food stores. Journal of Digital Contents Society, 20(8), 1491-1501.

Jo, J. H. (2018). In the franchise industry, O2O services are the way to live. Hyundai Economic Daily., Retrieved Auguest 21, 2018, from http://www.finomy.com/news/articleView.html?idxno=57391

Jun, Y.S. (2020, February). How to target the 'MZ generation' of new consumers in the low growth era, HankyungBusiness, 1265

Jung, B.-G. (2020). The effects of technology-based self-service on perceived value experience and revisit intention in korean style restaurants. FoodService Industry Journal, 16(1), 35-51

Kim, E.-J., Kim, S.-H., \& Lee, Y.-K. (2019). The effects of brand hearsay on brand trust and brand attitudes. Journal of Hospitality Marketing \& Management, 28(7), 765-784.

Kim, S-W (2020). The burgers and pizza industry's performance is 'joy and sorrow'. Toyo Economy, Retrieved April 29, 2020, from http://www.sateconomy.co.kr/news/articleView.html?idxno $=68871$ 
Krugman, H. E. (1965). The impact of television advertising: Learning without involvement. Public Opinion Quarterly, 29(3), 349-356.

Kunz, W., Schmitt, B., \& Meyer, A. (2011). How does perceived firm innovativeness affect the consumer? Journal of Business Research, 64(8), 816-822.

Leckie, C., Nyadzayo, M. W., \& Johnson, L. W. (2016). Antecedents of consumer brand engagement and brand loyalty. Journal of Marketing Management, 32(5-6), 558-578.

Leckie, C., Nyadzayo, M. W., \& Johnson, L. W. (2018). Promoting brand engagement behaviors and loyalty through perceived service value and innovativeness. Journal of Services Marketing, 32(1), 72-80.

Lee, H-S, \& Shim, H-J (2020). Food robot surges... Leading 'Untact Restaurant' MK, Retrieved May 22, 2020, from https://www.mk.co.kr/news/economy/view/2020/05/526887/

Lee, J. Y., Lee, M. J., Kwon, D. J., Jeong, S. Y., \& Hur, S. B. (2019). Impacts of food-service franchise's SNS marketing activities on customer behavior intention, Korean Journal of Franchise Management, 10(1), 43-52.

Lee, T-H, \& Jang, J-W (2019). Why do fast food companies invest in IT? InterBiz, Retrieved April 30, 2019, from https://blog.naver.com/businessinsight/221526355165

Leung, X. Y., \& Bai, B. (2013). How motivation, opportunity, and ability impact travelers' social media involvement and revisit intention. Journal of Travel \& Tourism Marketing, 30(1-2), 58-77.

Leventhal, R. C., Hollebeek, L. D., \& Chen, T. (2014). Exploring positively-versus negatively-valenced brand engagement: a conceptual model. Journal of Product \& Brand Management., 23(1), 62-74.

Mende, M., Thompson, S. A., \& Coenen, C. (2015). It's all relative: how customer-perceived competitive advantage influences referral intentions. Marketing Letters, 26(4), 661678.

Moore, G. C., \& Benbasat, I. (1991). Development of an instrument to measure the perceptions of adopting an information technology innovation. Information Systems Research, 2(3), 192-222.

Nam, M-J (2020). " "Unsafe outside the blanket"" Ttrendy contact service, destination?. InterBiz, Retrieved Feb 26, 2020, from https://blog.naver.com/businessinsight/221826041525

Nyer, P. U. (1997). A study of the relationships between cognitive appraisals and consumption emotions. Journal of the Academy of Marketing Science, 25(4), 296-304.

Oliver, R. (1997). Satisfaction: a behavioral perspective on the customer. In: New York: Irwin McGraw Hill.

Oliver, R. L. (1999). Whence consumer loyalty? Journal of Marketing, 63(4_suppl1), 33-44.

Pansari, A., \& Kumar, V. (2017). Customer engagement: The construct, antecedents, and consequences. Journal of the Academy of Marketing Science, 45(3), 294-311.

Petty, R. E., \& Cacioppo, J. T. (1986). The elaboration likelihood model of persuasion. In Communication and persuasion (pp.
1-24): Springer: New York, NY.

Pham, M. T., \& Avnet, T. (2009). Rethinking regulatory engagement theory. Journal of Consumer Psychology, 19(2), 115-123.

Ringel, M., Grassl, F., Baeza, R., Kennedy, D., Spira, M., \& Manly, J. (2019). The Most Innovative Companies 2019: Rise of AI, Platforms, and Ecosystems. The Boston Consulting Group (BCG). Retrived from March 21, 2019, https://www.bcg.com/publications/2019/most-innovativecompanies-innovation.aspx

Robertson, T. S. (1976). Low-commitment consumer behavior. Journal of Advertising Research., 16(2), 19-24.

Rogers, E. M. (2010). Diffusion of innovations: Simon and Schuster: New York.

Roh, H.S., Lee, S.H., Kim, S.H. (2020). A Comparative Study of Consumption Propensity and Determinants of Purchasing According to Cultural Differences between Baby Boomers and Millennials: Application to Franchise Customers. Korean Journal of Franchise Management, 11(1), 31-44

Samjung KPMG Economic Research Institute. (2020). Analysis of impacts by industry according to Corona 19. COVID-19 Business Report. Retrieved from https://home.kpmg/content/dam/kpmg/kr/pdf/2020/kr-covid19-industries-impact-20200327-.pdf

Schiffman, L. G., \& Kanuk, L. L. (1991). Consumer behavior, 4th Edition. In: Prentice Hall.

Smith, C. A., \& Ellsworth, P. C. (1985). Patterns of cognitive appraisal in emotion. Journal of Personality and Social Psychology, 48(4), 813-838.

Srinivasan, S. S., Anderson, R., \& Ponnavolu, K. (2002). Customer loyalty in e-commerce: An exploration of its antecedents and consequences. Journal of Retailing, 78(1), 4150.

Tenenhaus, M., Vinzi, V. E., Chatelin, Y.-M., \& Lauro, C. (2005). PLS path modeling. Computational Satistics \& Data Analysis, $48(1), 159-205$.

Touni, R., Kim, W. G., Choi, H.-M., \& Ali, M. A. (2020). Antecedents and an outcome of customer engagement with hotel brand community on Facebook. Journal of Hospitality \& Tourism Research, 44(2), 278-299.

Vivek, S. D., Beatty, S. E., \& Morgan, R. M. (2012). Customer engagement: Exploring customer relationships beyond purchase. Journal of Marketing Theory and Practice, 20(2), 122-146.

Wang, Y., Meister, D., \& Wang, Y. (2011). Reexamining relative advantage and perceived usefulness: An empirical study. International Journal of Information and Communication Technology Education , 7(1), 46-59.

Zaichkowsky, J. L. (1994). The personal involvement inventory: Reduction, revision, and application to advertising. Journal of Advertising, 23(4), 59-70.

Zaichkowsky, J. L. (1985). Measuring the involvement construct. Journal of Consumer Research, 12(3), 341-352. 


\section{Appendixes}

Appendix 1: Measurement model

\begin{tabular}{|c|c|c|c|c|}
\hline Constructs and Items & Factor loadings & $\alpha$ & $\mathrm{CR}^{\mathrm{a}}$ & AVE $^{\mathrm{b}}$ \\
\hline Involvement & & .912 & .934 & .741 \\
\hline Relevant & .842 & & & \\
\hline Needed & .878 & & & \\
\hline Useful & .842 & & & \\
\hline Important & .910 & & & \\
\hline Concern to me & .828 & & & \\
\hline Relative Advantages & & .894 & .927 & .761 \\
\hline Offering unique benefits & .806 & & & \\
\hline Higher quality than the competition & .874 & & & \\
\hline Solving problems I had with competitor services & .905 & & & \\
\hline Replacing a vastly inferior alternative & .901 & & & \\
\hline Cognitive Engagement & & .830 & .898 & .747 \\
\hline Using [brand's] products gets me to think about [brand name] brand. & .827 & & & \\
\hline I think about [brand] brand a lot when I am using their products. & .915 & & & \\
\hline Using [brand] products stimulates my interest to learn more about [brand] brand. & .848 & & & \\
\hline Affective Engagement & & .884 & .928 & .812 \\
\hline I feel very positive when I use [brand's] products. & .892 & & & \\
\hline Using [brand's] products make me happy. & .925 & & & \\
\hline I am proud to use [brand's] products. & .887 & & & \\
\hline Store Loyalty & & .885 & .921 & .746 \\
\hline I am willing to do business with [store] in the near future. & .850 & & & \\
\hline I will frequently buy at the [store]. & .909 & & & \\
\hline I will continue to buy at the [store] in the future. & .905 & & & \\
\hline I will like to spend more time to find [store]. & .786 & & & \\
\hline
\end{tabular}

${ }^{a} \mathrm{CR}$ : Composite reliability

${ }^{\mathrm{b}} \mathrm{AVE}$ : Average variance extracted

Appendix 2: Fornell-Larcker Criterion, Mean, and Standard Deviation (SD)

\begin{tabular}{|c|c|c|c|c|c|c|}
\hline & & 1 & 2 & 3 & 4 & 5 \\
\hline 1. & Involvement & .860 & & & & \\
\hline 2. & Relative advantage & 602 & .872 & & & \\
\hline 3. & Cognitive processing & .519 & .444 & .864 & & \\
\hline 4. & Affection & .612 & .634 & .537 & .901 & \\
\hline 5. & Loyalty & .658 & .710 & .520 & .703 & .864 \\
\hline & Mean & 4.586 & 4.449 & 4.726 & 4.922 & 4.98 \\
\hline & SD & 1.184 & 1.186 & 1.119 & 1.165 & 1.148 \\
\hline
\end{tabular}

Bold numbers indicate the square root of AVE 
Appendix 3: Structural estimates (PLS)

\begin{tabular}{|c|c|c|c|c|c|c|c|}
\hline & \multicolumn{3}{|c|}{ Paths } & \multirow{2}{*}{$\begin{array}{c}\text { Estimate } \\
.394\end{array}$} & \multirow{2}{*}{$\begin{array}{c}\text { t-value } \\
4.733\end{array}$} & \multirow{2}{*}{$\frac{\mathbf{p}}{.000^{* *}}$} & \multirow{2}{*}{$\begin{array}{c}\text { Results } \\
\text { Supported }\end{array}$} \\
\hline $\mathrm{H} 1$ & Involvement & $\rightarrow$ & Cognitive engagement & & & & \\
\hline $\mathrm{H} 2$ & Involvement & $\rightarrow$ & Affective engagement & .269 & 3.622 & $.000^{* *}$ & Supported \\
\hline H3 & Relative advantages & $\rightarrow$ & Cognitive engagement & .206 & 2.447 & $.014^{*}$ & Supported \\
\hline $\mathrm{H} 4$ & Relative advantages & $\rightarrow$ & Affective engagement & .368 & 5.201 & $.000^{* *}$ & Supported \\
\hline H5 & $\begin{array}{c}\text { Cognitive } \\
\text { engagement }\end{array}$ & $\rightarrow$ & Affective engagement & .234 & 3.452 & $.001^{* *}$ & Supported \\
\hline $\mathrm{H} 6$ & $\begin{array}{c}\text { Cognitive } \\
\text { engagement }\end{array}$ & $\rightarrow$ & Store loyalty & .201 & 3.070 & $.002^{* *}$ & Supported \\
\hline $\mathrm{H} 7$ & Affective engagement & $\rightarrow$ & Store loyalty & .595 & 10.018 & $.000^{* *}$ & Supported \\
\hline & & & & \multicolumn{3}{|c|}{$\mathbf{R}^{2}$} & $\mathbf{Q}^{2}$ \\
\hline \multicolumn{4}{|c|}{ Cognitive engagement } & \multicolumn{3}{|c|}{.524} & .418 \\
\hline \multicolumn{4}{|c|}{ Affective engagement } & \multicolumn{3}{|c|}{.296} & .213 \\
\hline \multicolumn{4}{|c|}{ Store loyalty } & \multicolumn{3}{|c|}{.522} & .379 \\
\hline
\end{tabular}

${ }^{*} p<.01,{ }^{* *} p<.001$, n.s.: not significant 